\title{
The antimicrobial susceptibility of Chlamydia trachomatis in cell culture
}

\author{
G. L. RIDGWAY, J. M. OWEN, AND J. D. ORIEL \\ From the Departments of Clinical Microbiology and Genitourinary Medicine, \\ University College Hospital, London
}

SUMMARY The action of 22 antimicrobial agents against the $\mathrm{SA}_{2} \mathrm{f}$ strain of Chlamydia trachomatis has been studied by the use of a simple cell culture technique. Tests for bactericidal activity were undertaken with some of the agents, and latency of infection was demonstrated. The susceptibilities of 10 clinical strains of $C$. trachomatis and of $\mathrm{SA}_{2}$ f to oxytetracyline, erythromycin, and spectinomycin in cell culture were found to be identical.

\section{Introduction}

The importance of Chlamydia trachomatis as a pathogen in the human genital tract is now well recognised, but the study of the action of antimicrobial agents against Chlamydia in vitro, an essential preliminary to rational treatment, was long hampered by the lack of a simple and reliable experimental system. Early work with embryonated chicken egg yolk sacs and with animal models (Werner, 1961) yielded valuable data, but the methods were slow and cumbersome. Recently, however, advances in cell culture systems (Gordon and Quan, 1965; Wentworth and Alexander, 1974) have made the in vitro testing of antimicrobial drugs against Chlamydia much easier. We have described a technique with which eight drugs were tested against a laboratory-maintained strain of C. trachomatis $\left(\mathbf{S A}_{2} \mathbf{f}\right)$ in McCoy cell cultures (Ridgway et al., 1976), and Kuo et al. (1977) investigated the action of seven drugs against the 15 known immunotypes of $C$. trachomatis in HeLa 229 cell cultures.

In the experiments reported here we have extended our earlier study in three directions: (1) We have estimated the minimum inhibitory concentration (MIC) of 22 antimicrobial agents against $\mathrm{SA}_{2} \mathrm{f}$. As before, MIC is defined as the lowest concentration of drug preventing the appearance of any chlamydial inclusions in the cell monolayers. (2) The minimum cidal concentration (MCC) of eight agents against $\mathrm{SA}_{2} \mathrm{f}$ was estimated. MCC is defined as the minimum

Address for reprints: G. L. Ridgway, Department of Clinical Microbiology and Genitourinary Medicine, University College Hospital, London WC1

Received for publication 13 October 1977 concentration of drug required to prevent further infection of the cell monolayers, even after multiple passage. C. trachomatis infections exhibit latency (Hanna et al., 1968), so for any particular drug the MIC and MCC may not necessarily be the same. (3) To see whether experience derived from studies with $\mathrm{SA}_{2} \mathrm{f}$ can be applied to clinical isolates of C. trachomatis, the MIC of various antimicrobial agents against $\mathrm{SA}_{2} \mathrm{f}$ and against 10 freshly isolated strains of Chlamydia were compared.

\section{Materials and methods}

The organism used for most of this work was the $\mathrm{SA}_{2} \mathrm{f}$ strain of $C$. trachomatis, but some experiments were also done with low passage isolates from patients with non-gonococcal urethritis or cervicitis.

\section{DETERMINATION OF MIC}

The method has been described elsewhere (Ridgway et al., 1976). Briefly, doubling dilutions of the antimicrobial agent were prepared in agent-free Chlamydia growth medium. One millilitre of each dilution was added to a flat-bottomed plastic tube containing a coverslip monolayer of 5-iodo-2deoxyuridine (IUDR) treated McCoy cells. A suspension of Chlamydia containing approximately 200 inclusion-forming units per $\mathrm{ml}$ was added to each tube. After centrifugation at $3000 \mathrm{~g}$ for an hour, the tubes were incubated for between 38 and 40 hours at $35^{\circ} \mathrm{C}$. The coverslips were removed and the cell monolayer was fixed with methanol and stained either with Giemsa for examination of autofluorescence using darkground illumination, or with iodine for examination of stained inclusions by brightfield illumination. Both methods of staining 
were used in case some of the antimicrobial agents affected only one, as is known to happen, for example, with penicillins which inhibit glycogen production with the consequent formation of inclusions which stain poorly with iodine (Jawetz, 1969). The MIC was taken as the lowest concentration containing no inclusions with either staining method.

\section{DETERMINATION OF MCC}

Four tubes containing IUDR-treated McCoy cells were prepared for each dilution of antimicrobial drug, and inoculated and incubated as above. After incubation, the coverslips from two tubes were fixed and stained, one with Giemsa and the other with iodine. The medium was removed from the remaining two tubes and replaced with $2 \mathrm{ml}$ of medium free from antimicrobial drugs. The cells were rubbed off the coverslip with a sterile rubbertipped glass rod, resuspended in the medium, and used to inoculate two further tubes containing fresh coverslip monolayers of IUDR-treated McCoy cells. Thus the contents of the two tubes were passaged into four tubes. After centrifugation, tubes were incubated in the usual manner. This passage procedure was repeated as required, and the MCC was taken as the lowest concentration of antimicrobial agent preventing demonstrable inclusions after 10 passages.

Strict precautions were taken to prevent crosscontamination with Chlamydia. No other work with this organism was undertaken while passage experiments were being performed, safety cabinets were always used, and work proceeded from higher to lower concentrations of antimicrobial agent.

\section{Results}

MIC

Table 1 shows the MIC of various antimicrobial agents to the $\mathrm{SA}_{2} \mathrm{f}$ strain. For all drugs except penicillins, cephalosporins, and folic acid antagonists (sulphamethoxazole and trimethoprim) the end point was sharp, and was the same whether Giemsa or iodine staining was used. Penicillins, cephalosporins, and the folic acid antagonists produced abnormal forms which often persisted throughout the dilutions tested. The MIC of these drugs was taken to be the lowest concentration which showed no autofluorescent inclusions on darkground examination; this coincided with the predominance of the abnormal forms over the normal inclusions. To determine whether the abnormal inclusions were viable, multiple passage was performed with some agents.

MCC

A typical result of a test for the MCC of an antimicrobial agent is shown for sulphamethoxazole in Table 2. In this case, no tubes yielded inclusions after the sixth passage. It will be seen that several 'blind' passages were necessary before inclusions could be seen by light microscopy in tubes containing concentrations below the MCC. The results for all the drugs tested by passage are shown in Table 3 . The number of passages required before no further tubes yielded inclusions varied between drugs, but was constant for each.

\section{CLINICAL ISOLATES}

The action of oxytetracycline, erythromycin, and spectinomycin was assessed against 10 strains of C. trachomatis recovered from patients with NGU or cervicitis, using $\mathrm{SA}_{2} \mathrm{f}$ as a control. The results are shown in Table 4. There was no marked difference between the results obtained with these isolates and with $\mathrm{SA}_{2}$ f.

\section{Discussion}

$\mathrm{SA}_{2} \mathrm{f}$ is immunologically identical with the LGV II serotype (Wang and Grayston, 1970), which crossreacts with Groups $B$ and ED, immunotypes

Table 1 Minimal inhibitory concentrations (MIC) of various antimicrobial agents against Chlamydia trachomatis $\left(\mathrm{SA}_{2} f\right)$ in cell culture

\begin{tabular}{|c|c|c|c|c|c|}
\hline \multicolumn{2}{|l|}{ High activity } & \multicolumn{2}{|l|}{ Medium activity } & \multicolumn{2}{|l|}{ Low activity } \\
\hline Antimicrobial & $M I C(\mu g / m l)$ & Antimicrobial & $M I C(\mu g / m l)$ & Antimicrobial & $M I C(\mu g / m l)$ \\
\hline $\begin{array}{l}\text { Rifampicin } \\
\text { Doxycycline } \\
\text { Minocycline } \\
\text { Oxytetracycline } \\
\text { Erythromycin (base } \\
\text { and lactobionate) }\end{array}$ & $\begin{array}{l}0.007 \\
0.03 \\
0.03 \\
0.06 \\
0.06\end{array}$ & $\begin{array}{l}\text { Ampicillin } \\
\text { Mecillinam } \\
\text { Penicillin } \\
\text { Clindamycin } \\
\text { Rifamide } \\
\text { Amoxycillin } \\
\text { Cephaloridine } \\
\text { Sulphamethoxazole } \\
\text { Chloramphenicol }\end{array}$ & $\begin{array}{l}0 \cdot 25 \\
0 \cdot 25 \\
1 \cdot 0 \\
1 \cdot 0 \\
1 \cdot 0 \\
2 \cdot 0 \\
2 \cdot 0 \\
4 \cdot 0 \\
4 \cdot 0\end{array}$ & $\begin{array}{l}\text { Spectinomycin } \\
\text { Oxolinic acid } \\
\text { Trimethoprim } \\
\text { Cefuroxime } \\
\text { Lincomycin } \\
\text { Vancomycin } \\
\text { Metronidazole } \\
\text { Gentamicin }\end{array}$ & $\begin{array}{r}64 \\
128 \\
128 \\
256 \\
512 \\
>256 \\
>256 \\
>512\end{array}$ \\
\hline
\end{tabular}


Table 2 Recovery of Chlamydia trachomatis $\left(\mathrm{SA}_{2} f\right)$ after initial incubation with sulphamethoxazole

\begin{tabular}{|c|c|c|c|c|c|c|c|c|c|c|c|}
\hline \multirow[b]{2}{*}{ Concentration of sulphamethoxazole $(\mu \mathrm{g} / \mathrm{ml})$} & \multicolumn{11}{|c|}{ Passage number } \\
\hline & 0 & 1 & 2 & 3 & 4 & 5 & 6 & 7 & 9 & 9 & 10 \\
\hline $1 \cdot 0$ & + & - & $+1-$ & $+1-$ & + & ND & ND & ND & ND & ND & ND \\
\hline $2 \cdot 0$ & + & - & - & - & + & ND & ND & ND & ND & ND & ND \\
\hline $4 \cdot 0$ & $(-)$ & - & - & - & - & + & ND & ND & ND & ND & ND \\
\hline $8 \cdot 0$ & $(-)$ & - & - & - & - & - & + & ND & ND & ND & ND \\
\hline 16.0 & $(-)$ & - & - & - & - & - & + & ND & ND & ND & ND \\
\hline $32 \cdot 0$ & $(-)$ & - & - & - & - & - & - & - & - & - & - \\
\hline
\end{tabular}

+ Giemsa-stained autofluorescent inclusions

(-) Autofluorescence absent; tiny abnormal inclusions present

- Inclusions not seen by light microscopy

ND Not done

MIC and MCC of sulphamethoxazole in this experiment were $4 \mu \mathrm{g} / \mathrm{ml}$ and $32 \mu \mathrm{g} / \mathrm{ml}$ respectively

Table 3 Relationship between minimum inhibitory concentration and minimum cidal concentration for various antimicrobial agents against Chlamydia trachomatis $\left(S A_{2} f\right)$

\begin{tabular}{lccc}
\hline Antimicrobial agent & $\begin{array}{l}\text { Minimum inhibitory concentration } \\
(\mu \mathrm{g} / \mathrm{ml})\end{array}$ & $\begin{array}{c}\text { Minimum cidal concentration } \\
(\mu \mathrm{g} / \mathrm{ml})\end{array}$ & $\begin{array}{c}\text { No. of passages required for } \\
\text { cidal end-point }\end{array}$ \\
\hline Oxytetracycline & $0 \cdot 06$ & $0 \cdot 25$ & 2 \\
Erythromycin & $0 \cdot 06$ & $0 \cdot 5$ & 3 \\
Mecillinam & $0 \cdot 25$ & $>1 \cdot 0$ & 2 \\
Cephaloridine & $2 \cdot 0$ & $>32 \cdot 0$ & 3 \\
Sulphamethoxazole & $4 \cdot 0$ & $32 \cdot 0$ & 6 \\
Spectinomycin & 64 & 128 & 1 \\
Trimethoprim & 128 & $>512$ & 3 \\
Cefuroxime & 256 & 1 \\
\hline
\end{tabular}

Table 4 Minimum inhibitory concentrations of various antimicrobial agents to clinical isolates of Chlamydia trachomatis in cell culture

\begin{tabular}{lllll}
\hline Strain no. & Serotype & Oxytetracycline $(\mu \mathrm{g} / \mathrm{ml})$ & Erythromycin $(\mu \mathrm{g} / \mathrm{ml})$ \\
\hline 1 & E & 0.03 & 0.06 \\
2 & DE & 0.03 & 0.03 & 32 \\
3 & DE & 0.06 & 0.03 & 6.12 \\
4 & G & 0.06 & 0.06 & 32 \\
5 & DE & 0.06 & 0.03 & 6.03 \\
6 & D & 0.03 & 0.03 & 64 \\
7 & D & 0.06 & 0.03 & 64 \\
8 & D & 0.06 & 0.03 & 64 \\
9 & D & 0.06 & 0.06 & 64 \\
SA & D & LGV II & 0.06 & 64 \\
\hline
\end{tabular}

commonly associated with human genital infections. In the present study the MICs of oxytetracycline, erythromycin, and streptomycin against 10 genital strains and $\mathrm{SA}_{2} \mathrm{f}$ were closely similar. All but one of these clinical isolates were in the DE complex of immunotypes, reflecting their genital origin, but Kuo et al. (1977), who tested all the 15 known immunotypes of $C$. trachomatis, found only minor differences between their responses to tetracycline and erythromycin. Thus, $\mathrm{SA}_{2} \mathrm{f}$ appears to be a suitable organism in evaluating the anti-chlamydial action of antimicrobial drugs for use in genital tract infections, and it also has the advantages of being readily available and safe to laboratory workers.
Rifampicin was the most active of the drugs tested, but it has not been evaluated clinically for the treatment of genital tract infections. The tetracyclines and erythromycin are both highly active against Chlamydia, as earlier work with laboratory models has shown (Jawetz, 1969). There was a marked difference between the MICs of lincomycin and clindamycin, between rifampicin and rifamide, and between cephaloridine and cefuroxime. It is possible that these differences are owing to variations in the cell-penetrating properties of the antibiotics. The activity of related antimicrobial agents evidently cannot be predicted from the results obtained for one member of the group. 
With some drugs there was a considerable difference between the MIC and the MCC. This was particularly apparent with the cell wall inhibitors, mecillinam and cephaloridine, and with the folic acid antagonists, sulphamethoxazole and trimethoprim. It is well known that cell wall inhibitors, such as penicillin, promote the formation of abnormal chlamydial inclusions. Johnson and Hobson (1977) were unable to render these abnormal forms viable by replacing the penicillin-containing medium with penicillin-free medium, without passage. However, Kuo et al. (1977), using single passage, demonstrated large differences between MIC values for infectivity and for viability of both penicillin and ampicillin against strains of $C$. trachomatis. Our own studies with mecillinam indicate that these inclusions readily recover their infectivity on passage on to fresh cell monolayers in medium free from antimicrobial drugs, but that multiple passage may be necessary.

The data summarised in Table 3 indicate that after the action of some agents it may be impossible to see chlamydial inclusions by microscopical examination, although after passage normal infectious inclusions may reappear. These observations suggest that within the system described here some antimicrobial drugs induce latency. In ocular chlamydial infections latency is thought to be common (Hanna et al., 1968), and it has been postulated that this is so for genital tract infections (Richmond et al., 1972), but latency with C. trachomatis has not previously been demonstrated in vitro.

MIC estimations broadly indicate which compounds are likely to be effective in the treatment of genital chlamydial infection; however, the results should be interpreted with caution, as in vitro the cidal concentration may differ considerably from the inhibitory concentration. Furthermore, if latency can be induced by antimicrobial drugs in vivo as well as in vitro, the concept of cure of these infections may require re-evaluation, and longer periods of follow-up after treatment than are currently practised may be advisable.

We are grateful to Dr E. Joan Stokes for kindly providing laboratory facilities, to Ms V. Lam Po Tang for technical assistance, and to Ms P. M. Waterworth for advice. Dr Brenda Thomas, Clinical Research Centre, Harrow, Middlesex, kindly undertook the immunotyping of the clinical isolates.

This work was supported by a grant from the Medical Research Council.

\section{References}

Gordon, F. B., and Quan, A. L. (1965). Isolation of the trachoma agent in cell culture. Proceedings of the Society for Experimental Biology and Medicine, 118, 354-359.

Hanna, L., Dawson, C. R., Briones, O., Thygeson, P., and Jawetz, E. (1968). Latency in human infections with TRIC agents. Journal of Immunology, 101, 43-50.

Jawetz, E. (1969). Chemotherapy of chlamydial infections. Advances in Pharmacology and Chemotherapy, 12, 253-282.

Johnson, F. W. A., and Hobson, D. (1977). The effect of penicillin on genital strains of Chlamydia trachomatis in tissue culture. Journal of Antimicrobial Chemotherapy, 3, 49-56.

Kuo, C. C., Wang, S. P., and Grayston, J. T. (1977). Antimicrobial activity of several antibiotics and a sulfonamide against Chlamydia trachomatis organisms in cell culture. Antimicrobial Agents and Chemotherapy, 12, 80-83.

Richmond, S. J., Hilton, A. L., and Clarke, S. K. R. (1972). Chlamydial infection. Role of Chlamydia sub-group $\mathrm{A}$ in non-gonococcal and post-gonococcal urethritis. British Journal of Venereal Diseases, 48, 437-444.

Ridgway, G. L., Owen, J. M., and Oriel, J. D. (1976). A method for testing antibiotic susceptibility of $C$. trachomatis in a cell culture system. Journal of Antimicrobial Chemotherapy, 2, 77-81.

Wang, S. P., and Grayston, J. T. (1970). Studies on the identity of the 'fast' egg-killing strains. In Trachoma and Related Diseases, pp. 323-336. Edited by R. L. Nichols. Excerpta Medica : Amsterdam.

Wentworth, B. B., and Alexander, E. R. (1974). Isolation of Chlamydia trachomatis by use of 5-iodo-2-deoxyuridine-treated cells. Applied Microbiology, 27, 912-916.

Werner, G. H. (1961). Recherches expérimentales sur la chimotherapie du trachome. Annales de l'Institut Pasteur, 100, 93-108. 